(RESEARCH ARTICLE)

\title{
Molecular docking of some benzothiazoles derivatives as anticonvulsant agents
}

\author{
Sahil Banwala ${ }^{1,}{ }^{*}$, Karan Wadhwa ${ }^{1}$, Sukhbir Lal Khokra ${ }^{1}$ and Asif Husain ${ }^{2}$ \\ ${ }^{1}$ Institute of Pharmaceutical Sciences, Kurukshetra University, Kurukshetra, Haryana, 136119, India. \\ 2 Department of Pharmaceutical Chemistry, Faculty of Pharmacy, Jamia Hamdard, New Delhi-110062, India.
}

Publication history: Received on 28 August 2020; revised on 20 September 2020; accepted on 22 September 2020

Article DOI: https://doi.org/10.30574/wjarr.2020.7.3.0330

\begin{abstract}
Benzothiazole is one of the promising heterocyclic compounds in the medicinal chemistry, endowed with several therapeutic potentials. The present research endeavors the high throughput in silico screening of 66 designed benzothiazole derivatives as potent GABA-aminotransferase inhibitors in Molegro virtual docker software (Version 6.0) using $10 \mathrm{HV}$ as PDB. The docking results showed mol dock score of -73.63 and -62.45 for the standard drugs phenytoin and carbamazepine respectively, on the other hand, the benzothiazole derivatives SDZ3, SDZ4, SDZ5, SDZ6, SDZ13, SDZ16, SDZ19, SDZ21, SDZ32, SDZ51, and SDZ64 exhibited excellent mol dock score, ranged from -104.23 to -121.56. Apart from mol dock score, excellent hydrogen bonding with amino acids of PDB was observed in most of the studied compounds. Compound SDZ4, SDZ8, SDZ11, SDZ31, SDZ57, SDZ58, SDZ59, SDZ60, SDZ61, SDZ63, SDZ64, SDZ65, and SDZ66 showed 5 to 7 hydrogen bond interactions, however, the standard drug phenytoin showed H-bond interaction with 2 amino acid; N-Glu109 and N-Asn110 with bond length $2.86 \AA$ and $3.10 \AA$ A respectively, and 2 interaction with NAsn 110 and 0-Cys47 with bond length $3.00 \AA$, and $3.35 \AA$ respectively were observed in carbamazepine. Thus, the present study affirmed the significant anticonvulsant potential of some designed benzothiazole derivatives based on their mol dock values and other parameters when studies in silico and the obtained results will provide data support and offer perspectives in future researches to develop a potent anticonvulsant agent from these benzothiazole derivatives.
\end{abstract}

Keywords: Anti-convulsant activity; Benzothiazole; Carbamazepine; In silico; Phenytoin

\section{Introduction}

Traditional techniques are the extremely time-consuming and expensive methods to discover a new drug, so to overcome these disadvantages of ancient strategies, simpler and rational approaches have been introduced that supports the provision of structural details through virtual screening. Virtual screening approaches can be based on either structure-based or ligand-based drug design techniques. The structural approach to drug explains molecular linking up while ligand-based approaches discuss the interaction between quantitative structure response (QSAR) and pharmacophore modeling [1].

The molecular docking approach highlights the connection amid the material and the target molecule, which consequently envisage the binding affinity of molecules to build a stable supermolecule complex by determining the most well-liked direction with minimal free energy [2]. Although shape complementarities and simulation are two basic perspectives employed in molecular docking yet it is classified into three distinct categories illustrated in Figure 1. The present study was aimed to study in silico molecular docking of certain developed benzothiazoles derivatives as potent anticonvulsant agents.

\footnotetext{
* Corresponding author: Sahil Banwala

Institute of Pharmaceutical Sciences, Kurukshetra University, Kurukshetra, Haryana, 136119, India. 


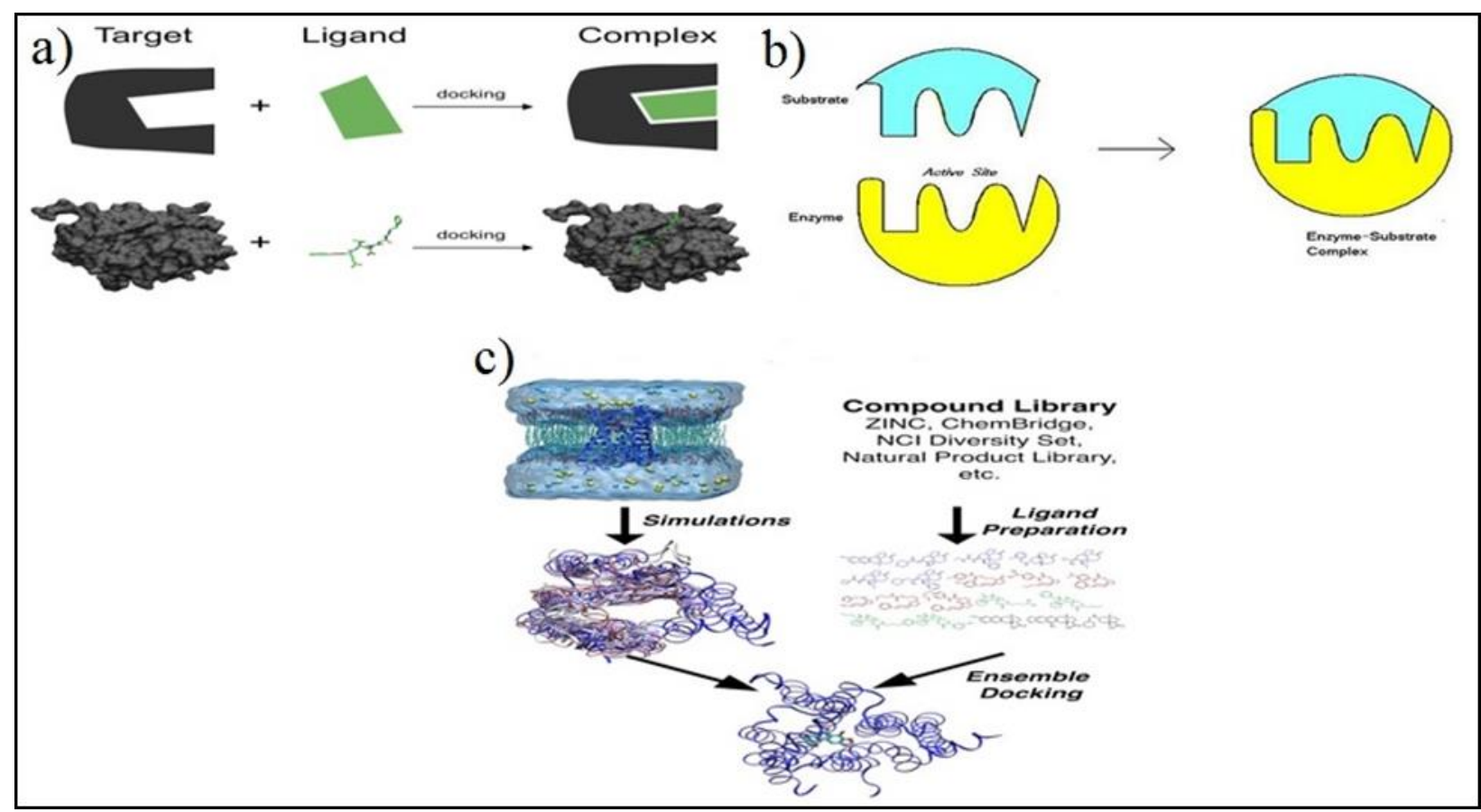

Figure 1 Techniques of molecular docking: (a) Induced work docking [3]; (b) Lock and key docking [4]; and (c) Ensemble docking [5]

Benzothiazole is a heterocyclic organo-sulfur product that is weakly basic. They are commonly used in bioorganic and medicinal chemistry of product development use. Sulfur and nitrogen atoms represent the central component of thiazole and other pharmacologically and biologically active compounds. The standard benzothiazole structure consists of a benzene ring fused with a 4, 5 thiazole position which is shown in Figure 2. The two rings combined and form the basic nucleus 1,3-benzothiazole [6]. The 1,3-benzothiazole ring has been observed to be a flexible pharmacophore to increase the level of the entire brain GABA, probably by Gamma-aminobutyric acid aminotransferase (GABA-AT) enzyme inhibition [7].

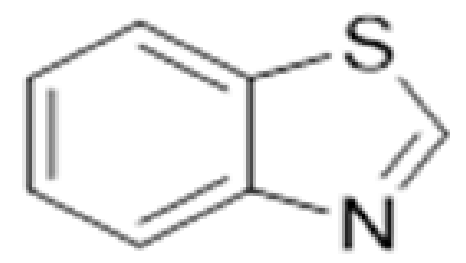

Figure 2 Structure of benzothiazole with basic ring

\section{The targets for anticonvulsant drug discovery}

A pyridoxal 5'-the phosphate-dependent enzyme. GABA-AT is responsible for the degradation of the GABA inhibitor. GABA-AT is a reliable aim for anti-epileptic medications since its systematic inhibition raises the production of GABA in the brain $[8,9]$. The neurotransmitter has 3 specific receptors: $G_{A B A}, G A B A_{B}$, and $G_{A B A}$. GABA $A_{A}$ receptors, linked to binding sites in the form of a receptive complex for benzodiazepines and barbiturates, the regular opening of in the chloride channel (post-synaptic channel connected to $\mathrm{Cl}$ ). When GABA is connected to the receptor group, it opens up and the chloride anions are hyperpolarized into the neuron. $\mathrm{GABA}_{\mathrm{B}}$ (pre-synaptic autoreceptors, $\mathrm{K}^{+}$currents mediated) receptors are metabotropic, associated with a cascade with second messages, while the physiological significance of ionotropic $\mathrm{GABA}_{\mathrm{C}}$ receptors is usually unknown, primarily in the retina. Tiagabine and Vigabatrin is the new anticonvulsant drug acting via the GABA-ergic mechanism. The former prevents the synthesis of GABA through neuronal and glial, while the latter raises GABA synaptic levels by GABA-AT inhibition. Gabapentin, designed simply to come into the brain as a precursor of GABA, has been shown to extend GABA synaptic brain. It reduces the influx of $\mathrm{Ca}^{2+}$ into neurons through a certain subunit of voltage-dependent calcium channels. A standard anticonvulsant drug usually inhibits sodium currents (Carbamazepine (CBZ), Phenytoin (PTN), phenobarbital, valproate), or enhance GABA-ergic 
inhibition (benzodiazepines, phenobarbital, valproate), whereas ethosuximide mainly controls the absence seizures, by reducing calcium currents via T-type calcium channels". Current anticonvulsant drugs (lamotrigine and oxcarbazepine) often produce anticonvulsant action by the suppression of voltage-dependent $\mathrm{Na}^{+}$channels. Due to the consequence of glutamate-mediated excitation, some antiepileptics are targeted at glutamatergic receptors (phenobarbital, felbamate, and topiramate). They inhibit metal currents in conjunction with them. Zonisamide, which appears to share the same mechanism, reduces free radicals jointly [10].

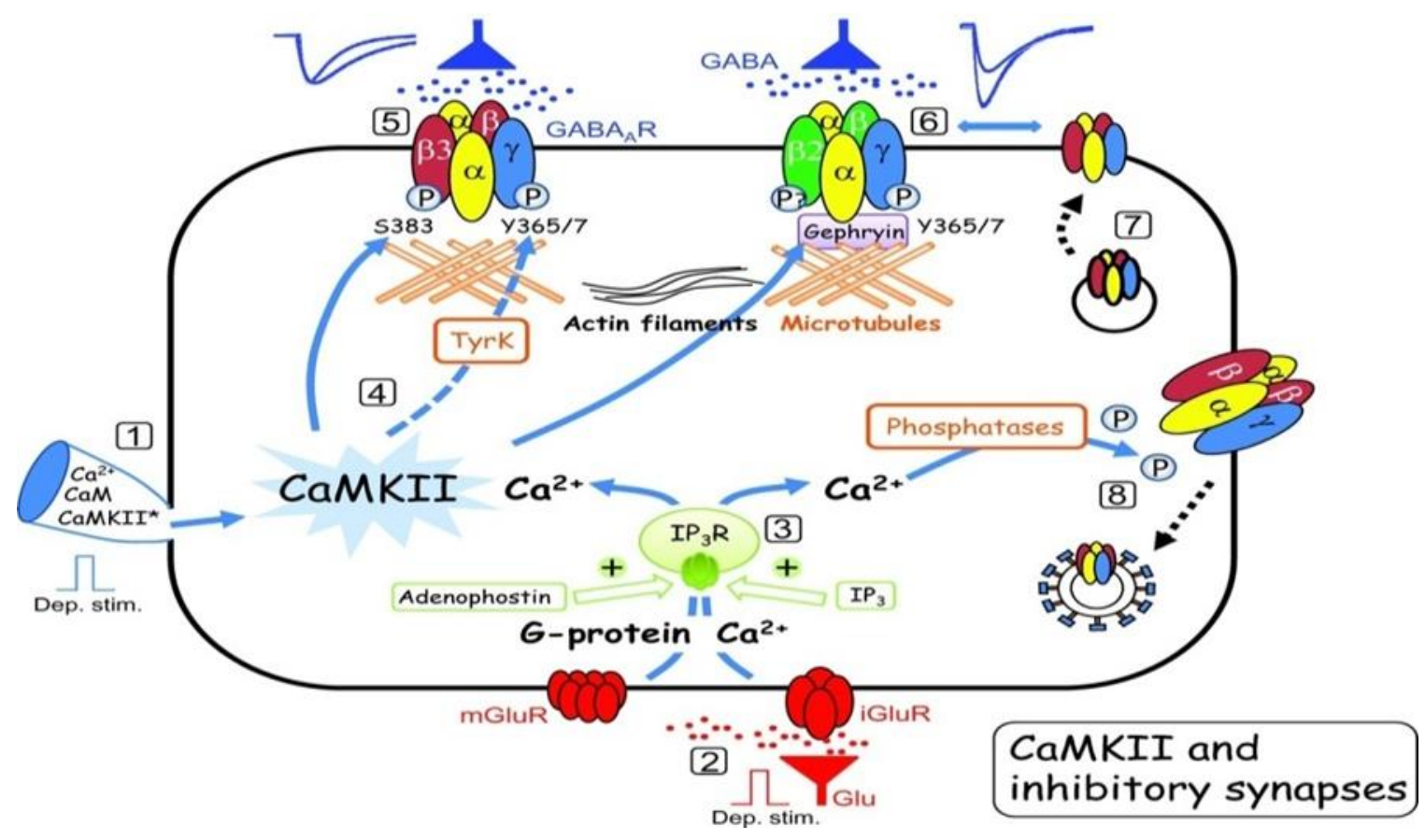

Figure 3 Targets for anticonvulsant drugs

The present research endeavors the high throughput in silico screening of 66 designed benzothiazole derivatives as potent GABA-AT inhibitors in Molegro virtual docker software (version 6.0) using 10HV as PDB and compared with two standard anticonvulsant drugs i.e. Carbamazepine (CBZ) and Phenytoin (PTN).

\section{Material and Methods}

Docking could be a technique to work out potential binding modes of a substance to the receptor site. Studies of docking with a group of experimental benzothiazole derivatives were carried out using Molegro virtual docker 6.0 on GABA subunits of 10HV. The X-ray structures of that were retrieved from the Protein Data Bank. Each ligand was determined to interact with the $10 \mathrm{HV}$ active location, which was the highest mol dock, hydrogen bonding, and rerank scores used during docking. Table 1 demonstrates the general arrangement of the analogs [11-14].

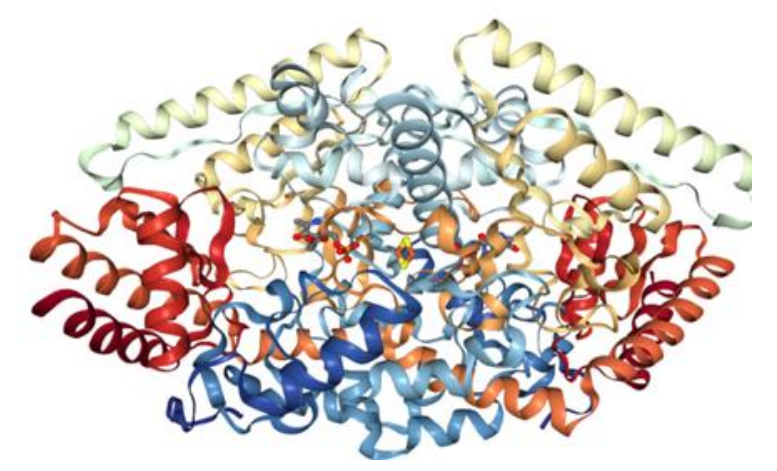

Figure 4 3D view of PDB- $10 \mathrm{HV}$ 


\subsection{The methodology can be divided into the following steps}

- Importing a protein file, ligand file, and preparation of ligands

- Preparation and identifications of protein molecule cavities

- Running the docking system using the docking wizard panel

- Determination of poses of protein-ligand complexes

- Calculations of Mol dock score, hydrogen bond interaction, and rerank score

\subsubsection{Selection of the compounds and ligand preparation}

The hypothetical compounds were selected based on literature. The ligand molecules were prepared by using Marvin Sketch (version 5.11.0) and then molecules were converted to 2D and then converted to 3D using build and optimize the method and then clean in 3D then add explicit hydrogens. The resulting structure will be saved in MDL Molfile $\left({ }^{*}\right.$.mol) format. Single, low energy, 3D structure with appropriate chiralities will be created for each successfully proposed structure. Then the generated structures were imported into the workspace of docking software Molegro Virtual Docker 6.0. The molecule can be incorporated into the MVD using MDL (sdf $/ \mathrm{sd} / \mathrm{mol} / \mathrm{mdl}$ ) file format which contains bonding formation. In this step, the preparation of molecules was assigned bonds, bond order and hybridization, charges, explicit hydrogens, and flexible torsion in ligands.

\subsubsection{Compound selection}

Based on literature data, we selected 66 hypothetical compounds and docking studies were performed using (PDB ID $10 \mathrm{HV}$ ) for anticonvulsant activity using Molegro Virtual Docker. The structure of all the 66 selected compounds is illustrated in Table 1.

\subsubsection{Set of hypothetical compounds}

A docking study was performed with a set of hypothetical benzothiazole derivatives. The basic moiety of compounds is shown in Figure 5

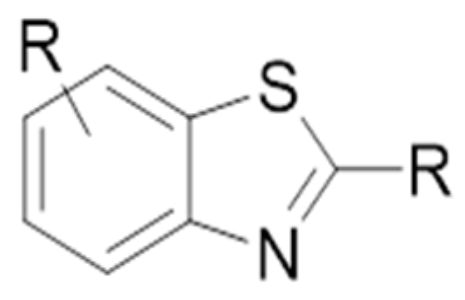

Figure 5 Basic moiety of developed compounds

\subsubsection{Protein preparation}

In Molegro Virtual Docker the step protein preparation is automatically done. Docking is a computational method for predicting modes of action of small organic molecules to protein receptors. It produces a picture of the active site with an interface point known as the grid. It holds the ligand in the receptor-binding region. Different forms of interactions between receptor and ligand van der Waal interactions, aromatic interactions are known to be used to quantify binding strength. The number of protein receptor (PDB) used in this study are PDB ID: 10HV. The PDB's used for docking were produced from RCSB (protein data bank).

\subsubsection{Ligand docking}

The ligand docking was accomplished by producing many ligands poses at the active site and a posing score to classify one or more poses that roughly resemble the bioactive conformation defined by X-ray crystallography. The Mol dock scoring function (Mol Dock Score), The E-score is determined by the following terms of energy:

$E_{\text {score }}=E_{\text {inter }}+E_{\text {intra }}$

(Equation 1)

Where $E_{\text {intra }}$ is the inter energy of the ligand;

$E_{\text {inter }}$ is the ligand-protein interaction energy 
Molegro Virtual Docker (Version 6.0) software is used to analyze binding modes of compounds with internal ligand PLP600. The interactions of standards (PTN, CBZ) and test compounds were compared and the score tabulated as mol dock score, re-rank score, and the number of hydrogen bond interactions. The docking energies of the ligands were negative, which shows the stable binding interaction between the receptor and the ligands.

Table 1 Hypothetical compounds used for docking analysis

\begin{tabular}{|c|c|c|c|}
\hline $\begin{array}{l}\text { Compound } \\
\text { Name }\end{array}$ & Structure of compounds & $\begin{array}{l}\text { Compound } \\
\text { Name }\end{array}$ & Structure of compounds \\
\hline PTN & & SDZ33 & \\
\hline CBZ & & SDZ34 & \\
\hline SDZ1 & & SDZ35 & \\
\hline SDZ2 & & SDZ36 & \\
\hline SDZ3 & & SDZ37 & \\
\hline SDZ4 & & & \\
\hline SDZ5 & & SDZ39 & \\
\hline
\end{tabular}


World Journal of Advanced Research and Reviews, 2020, 07(03), 166-180

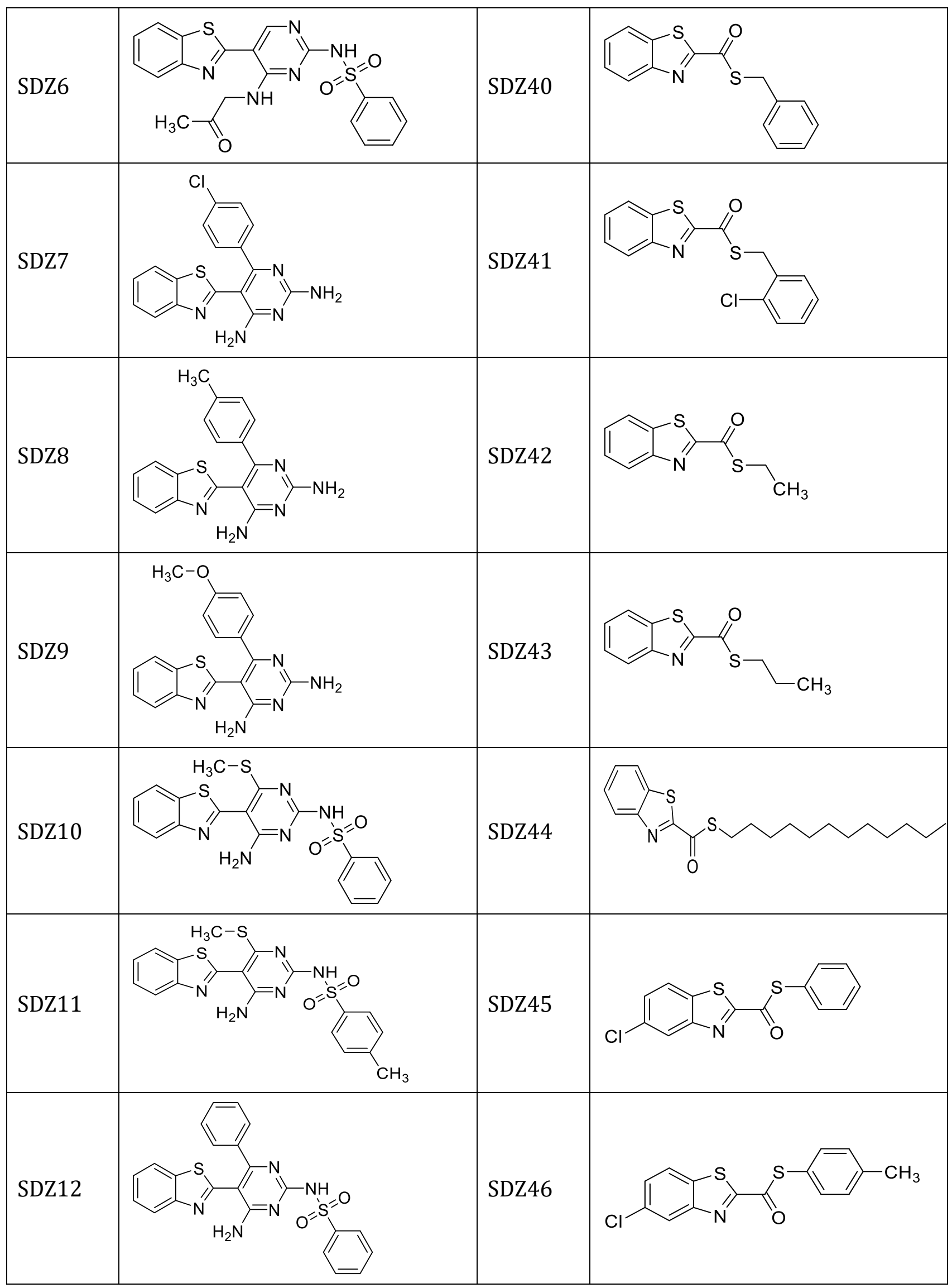

171 


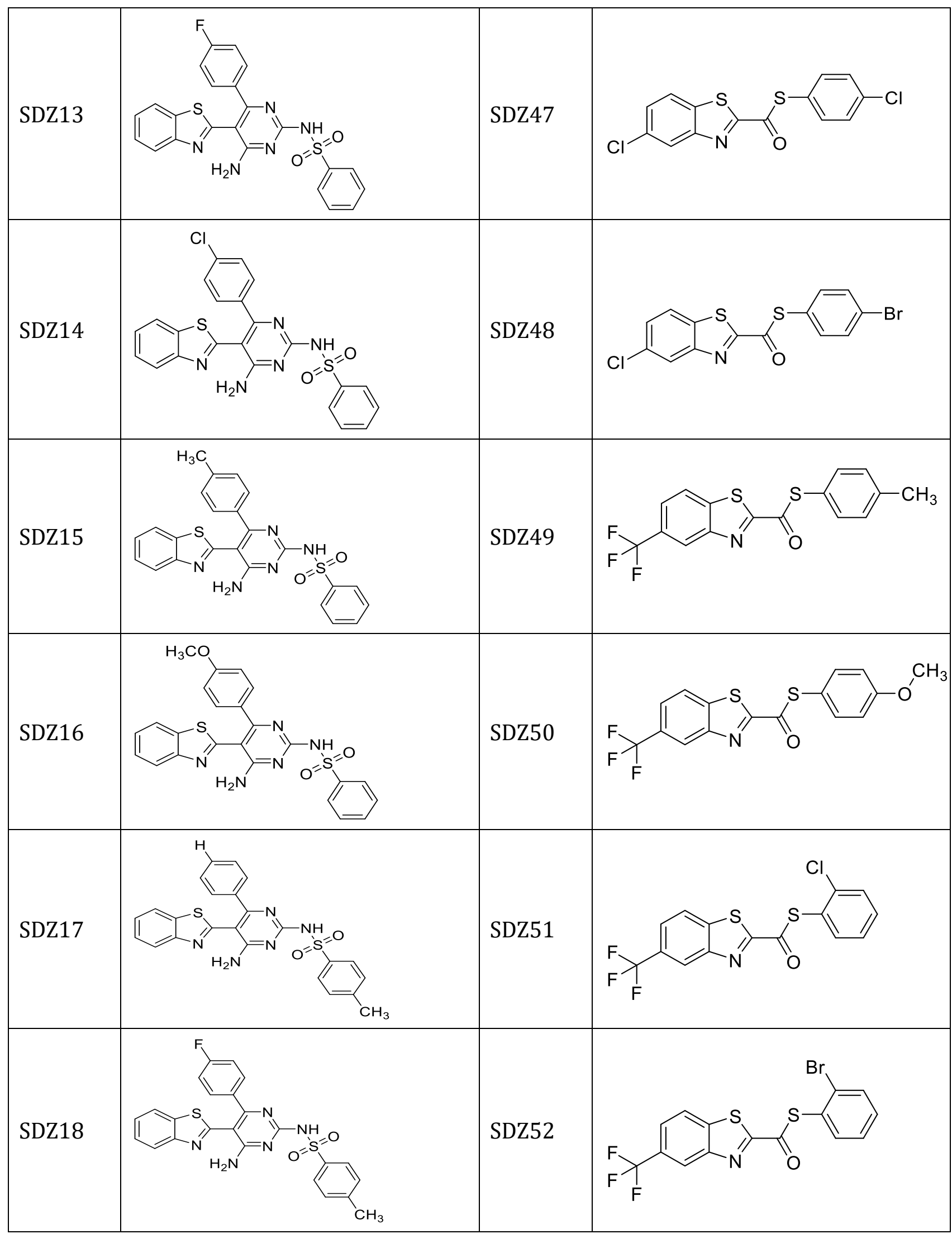




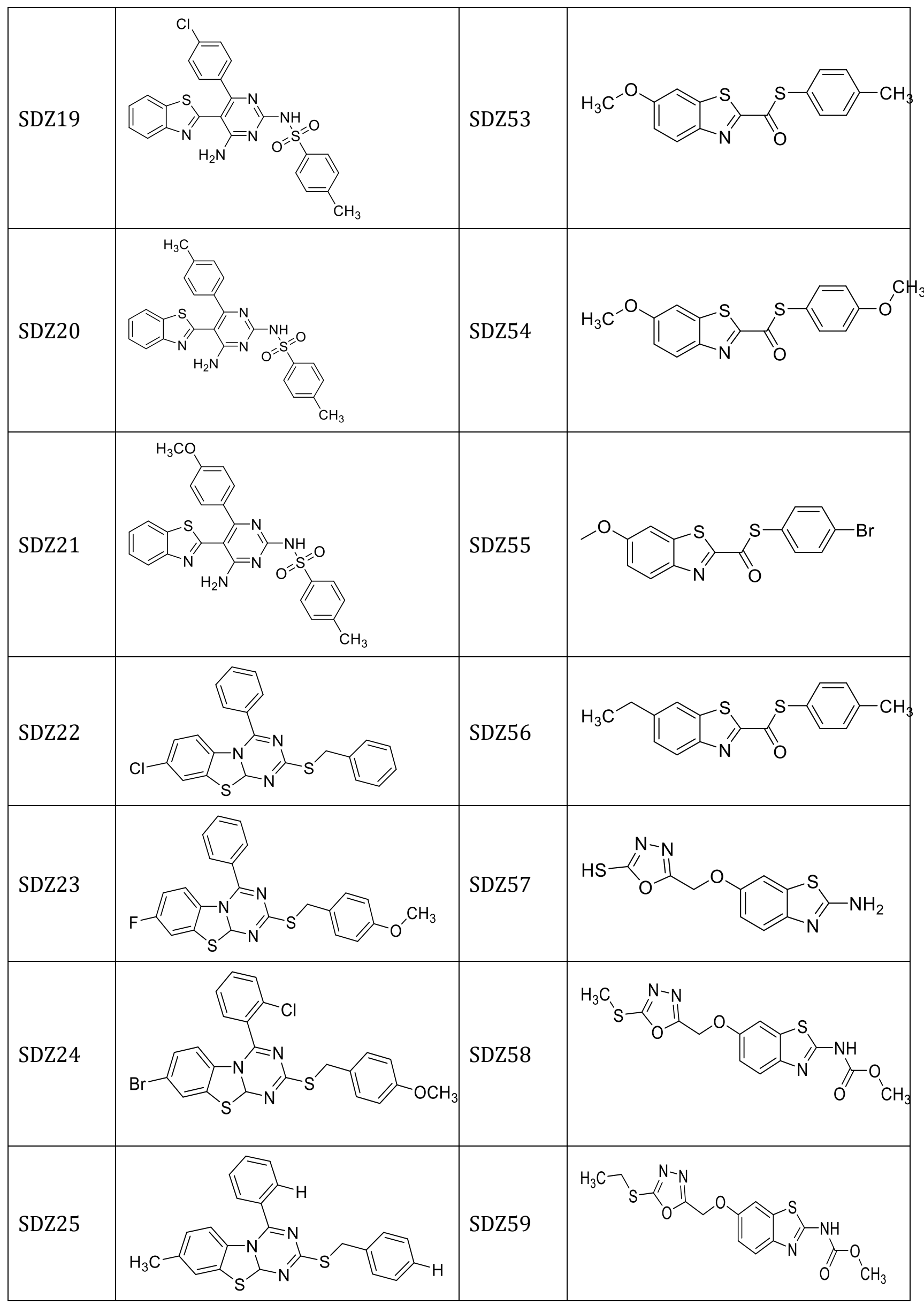


World Journal of Advanced Research and Reviews, 2020, 07(03), 166-180

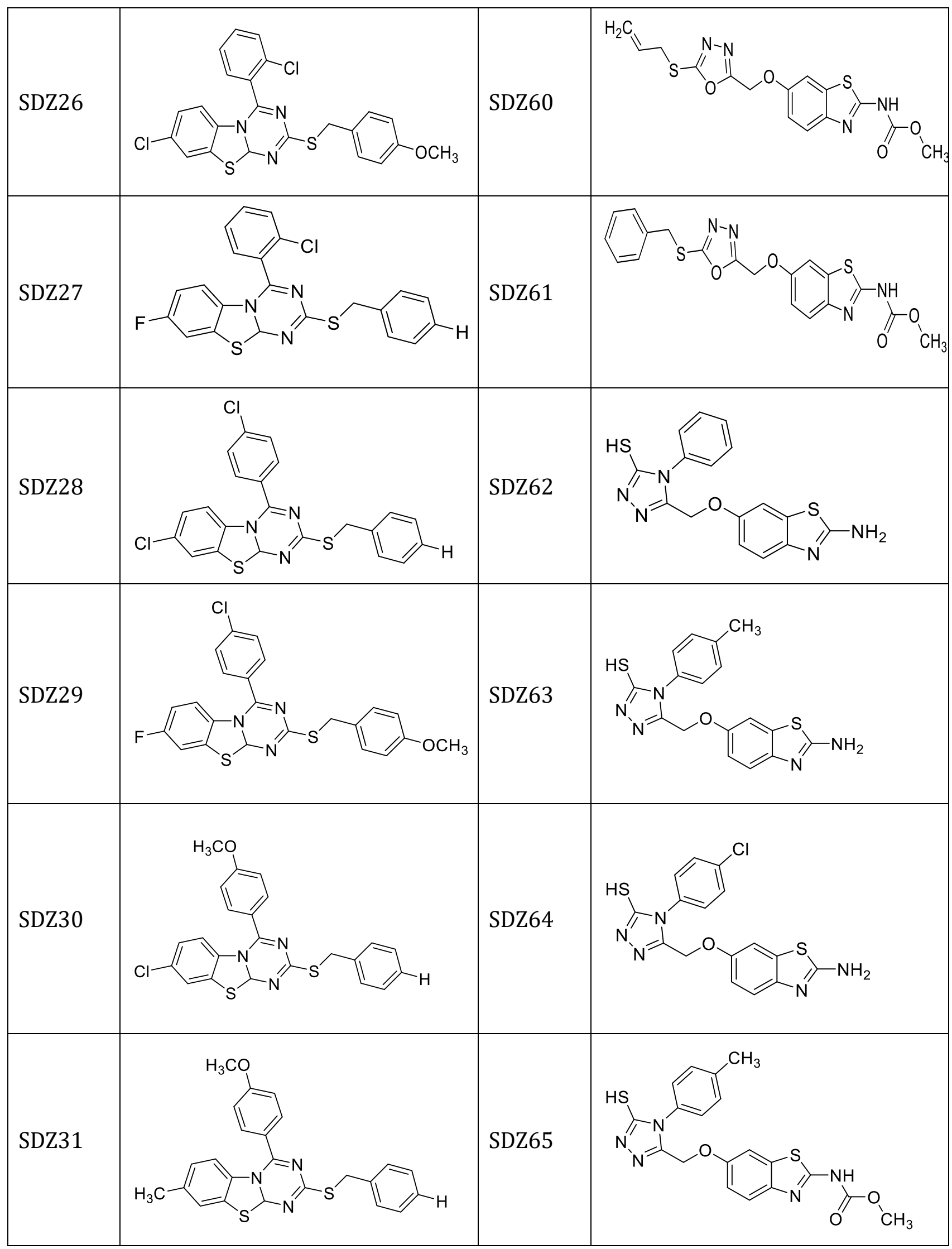

174 


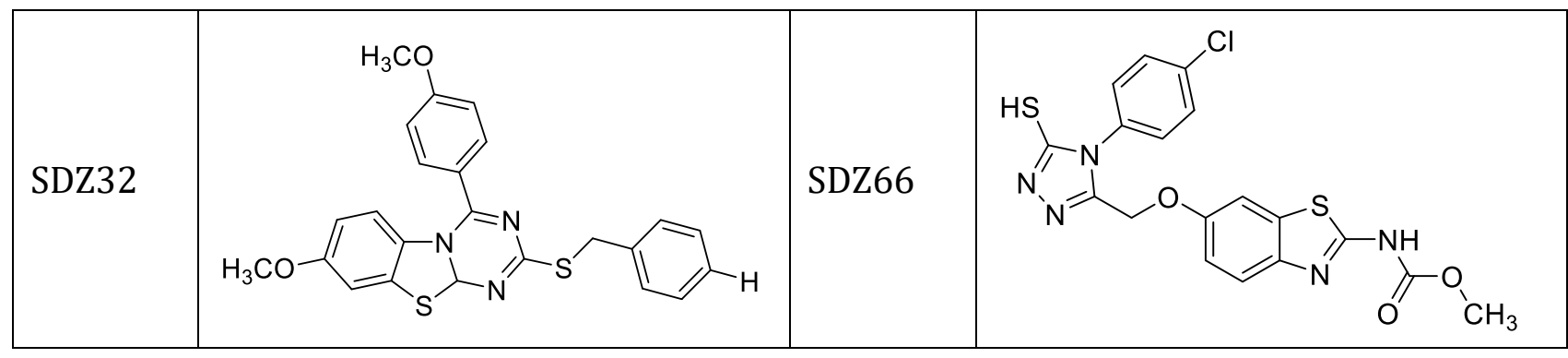

\section{Results and discussion}

The most significant aspects of docking are the association of the ligand with the putative binding site of the enzyme. In this article, we studied the docking of the sixty-six test compounds using PDB (10HV) with GABA-AT inhibitors taking PTN and CBZ as standard. All hypothetical compounds were found to possess moderate results for anticonvulsant activity. But out of sixty-six compounds, 22 compounds (SDZ4, SDZ6, SDZ7, SDZ8, SDZ11, SDZ14, SDZ17, SDZ18, SDZ19, SDZ20, SDZ21, SDZ31, SDZ57, SDZ58, SDZ59, SDZ60 SDZ61, SDZ62, SDZ63, SDZ64, SDZ65, and SDZ66) which we selected were found to possess best results for anti-epileptic activity. The standard drugs PTN and CBZ showed mol dock score -73.63 and -62.45 respectively, was found comparatively lower than the hypothetical compounds. Out of these sixty-six compounds, eleven compounds SDZ3, SDZ4, SDZ5, SDZ6, SDZ13, SDZ16, SDZ19, SDZ21, SDZ32, SDZ51, and SDZ64 showed very good mol dock score ranging between -104.23 to -121.56 while compounds SDZ12, SDZ14, SDZ15, SDZ18, SDZ20, SDZ22, SDZ23, SDZ24, SDZ27, SDZ31, SDZ52, and SDZ63 showed mol dock score ranging between -100.45 to -103.91 as compared to standard mol dock score values -73.63 and -62.45 respectively. It is concluded that the mol dock values of most of the test compounds were found greater than standard drugs except compounds SDZ38 and SDZ54. Most of the test compounds showed a very good number of hydrogen bond interactions viz compound SDZ4, SDZ8, SDZ11, SDZ31, SDZ57, SDZ58, SDZ59, SDZ60, SDZ6, SDZ63, SDZ64, SDZ65 \& SDZ66 which showed 5 to 7 number of hydrogen bond interactions as compared to standard drug interactions values 2 respectively. Test compounds that showed 4 number of hydrogen bond interactions are SDZ6, SDZ7, SDZ14, SDZ17, SDZ18, SDZ19, SDZ20, SDZ21, and SDZ62. The standard drug PTN showed H-bond interaction with amino acid N-Glu109, N-Asn110 with bond length 2.86 $\AA ̊$ and $3.10 \AA$ Å while CBZ showed interaction with $\mathrm{N}$-asn110, O-Cys47 with bond length $3.00 \AA$ and $3.35 \AA$ Å respectively. Most of the test compounds were found to showed interaction with the same amino acids Glu50 and Asn 110 and showed very acceptable bond length. The docking output of 66 compounds is given in Table 2 with details of interacting amino acids, bond length, no. of hydrogen bond interaction, Mol dock score, and re-ranks score. Figure 6 represents the drugreceptor interaction of standards drugs (PTZ and CBZ), whereas ligand-receptor interactions of compounds having good Mol dock scores were illustrated in Figure 7 and Figure 8.

Table 2 Ligand-receptor interaction of Benzothiazoles, Phenytoin, and Carbamazepine as standard drugs on PDB ID: (10HV) using Molegro software.

\begin{tabular}{|l|l|l|l|l|}
\hline Compound No. & $\begin{array}{l}\text { Interaction of amino acid with H-bond } \\
\text { (A) having the shortest bond length }\end{array}$ & $\begin{array}{l}\text { Number of } \\
\text { hydrogen bonds }\end{array}$ & $\begin{array}{l}\text { Mol dock } \\
\text { score }\end{array}$ & $\begin{array}{l}\text { Re-rank } \\
\text { score }\end{array}$ \\
\hline PTN & N-Asn110 (3.10); N-Glu109(2.86) & 2 & -73.63 & -60.75 \\
\hline CBZ & N-Asn110(3.00); O-Cys(3.35) & 2 & -62.45 & -53.39 \\
\hline $\begin{array}{l}\text { Internal ligand } \\
\text { PLP-600 [A] }\end{array}$ & $\begin{array}{l}\text { N-Glu109(3.00); N-Asn110(3.44); } \\
\text { O-Glu50(2.61) }\end{array}$ & 3 & -47.66 & -45.75 \\
\hline SDZ1 & O-Glu50 (2.67); O-Gln92(2.86) & 2 & -78.61 & -61.35 \\
\hline SDZ2 & $\begin{array}{l}\text { O-Glu109 (3.49); N-Asn48(2.80); } \\
\text { O-Glu50(3.51) }\end{array}$ & 3 & -84.82 & -63.44 \\
\hline SDZ3 & $\begin{array}{l}\text { N-Lys114(2.73); N-Asn110(3.21); } \\
\text { N-Glu109(3.57) }\end{array}$ & 3 & -114.75 & -79.84 \\
\hline SDZ4* & $\begin{array}{l}\text { N-Asn48(2.80); N-Asn48(2.86); } \\
\text { N-Asn110(3.26); N-Glu109(3.34); }\end{array}$ & 5 & -112.81 & -72.46 \\
\hline
\end{tabular}


World Journal of Advanced Research and Reviews, 2020, 07(03), 166-180

\begin{tabular}{|c|c|c|c|c|}
\hline & O-Glu50(2.70) & & & \\
\hline SDZ5 & N-Asn110(3.17); O-Glu109(2.60) & 2 & -117.74 & -79.14 \\
\hline SDZ6 ${ }^{*}$ & $\begin{array}{l}\text { N-Lys114(2.60); O-Asn93(3.32); } \\
\text { N-Glu109(2.94); N-Asn110(2.79) }\end{array}$ & 4 & -113.55 & -82.74 \\
\hline $\mathrm{SDZ7}^{*}$ & $\begin{array}{l}\text { O-Thr96(2.85); O-Glu50(2.96); } \\
\text { N-Glu109(3.56); O-Cys47(2.60) }\end{array}$ & 4 & -75.66 & -56.96 \\
\hline SDZ8* & $\begin{array}{l}\text { O-Cys47(2.60); O-Glu50(2.96); } \\
\text { O-Asn110(3.11); O-Thr96(2.84); } \\
\text { N-Glu109(3.56) }\end{array}$ & 5 & -75.21 & -56.86 \\
\hline SDZ9 & $\begin{array}{l}\text { O-Asn110(3.10); O-Glu117(2.71); } \\
\text { NAsn110(3.43) }\end{array}$ & 3 & -81.67 & -54.59 \\
\hline SDZ10 & N-Asn110(2.62); O-Gln92 (3.31) & 2 & -86.11 & -59.12 \\
\hline SDZ11 $^{*}$ & $\begin{array}{l}\text { O-Asn93(2.60); O-Gln92(2.66); } \\
\text { O-Gln50(3.04); N-Asn110(2.77); } \\
\text { N-Glu109(3.10) }\end{array}$ & 5 & -85.67 & -65.61 \\
\hline SDZ12 & 0-Asn110 (3.03); 0-Asn93 (2.13) & 2 & -103.58 & -72.15 \\
\hline SDZ13 & $\mathrm{N}-\mathrm{Asn} 48(3.11)$ & 1 & -113.40 & -76.29 \\
\hline SDZ14 $^{*}$ & $\begin{array}{l}\text { O-Glu50(3.28); O-Glu109(3.19); } \\
\text { O-Thr96(2.69); O-Asn110(2.48) }\end{array}$ & 4 & -101.51 & -70.79 \\
\hline SDZ15 & $\begin{array}{l}\text { N-Asn48(3.11); O-Asn48(3.24); } \\
\text { O-Glu109(2.67) }\end{array}$ & 3 & -103.46 & -74.44 \\
\hline SDZ16 & $\begin{array}{l}\text { O-Asn110(2.88); N-Glu109(3.10); } \\
\text { N-Asn110(2.55) }\end{array}$ & 3 & -110.43 & -77.27 \\
\hline SDZ17 $^{*}$ & $\begin{array}{l}\text { O-Glu50 (3.10); O-Gln92(2.86); } \\
\text { N-Asn93(3.10); N-Gln92(2.82) }\end{array}$ & 4 & -99.96 & -50.79 \\
\hline SDZ18* & $\begin{array}{l}\text { O-Glu150(3.10); O-Asn110(2.43) } \\
\text { O-Glu109(3.30); O-Thr96(2.60) }\end{array}$ & 4 & -103.91 & -68.97 \\
\hline SDZ19* & $\begin{array}{l}\text { O-Glu109(3.10); O-Glu50(3.33); } \\
\text { O-Asn110(2.56); O-Thr96(2.74) }\end{array}$ & 4 & -104.23 & -76.78 \\
\hline SDZ20* & $\begin{array}{l}\text { O-Glu109 (3.14); O-Asn110(2.56); } \\
\text { O-Thr96(2.90); O-Glu50(2.70) }\end{array}$ & 4 & -100.45 & -71.19 \\
\hline SDZ21 $^{*}$ & $\begin{array}{l}\text { N-Asn110(3.10); O-Glu109(3.29); } \\
\text { N-Glu92(3.50); N-Glu109(3.51) }\end{array}$ & 4 & -121.56 & -68.06 \\
\hline SDZ22 & -------------- & No interaction & -101.81 & -78.05 \\
\hline SDZ23 & N-Asn110 (2.97); N-Glu109(3.11) & 2 & -101.41 & -53.85 \\
\hline SDZ24 & ------------ & No interaction & -103.79 & -57.96 \\
\hline SDZ25 & -------------- & No interaction & -96.62 & -60.57 \\
\hline SDZ26 & 0-Thr96(3.24) & 1 & -95.65 & -51.43 \\
\hline SDZ27 & ------------ & No interaction & -102.77 & -62.89 \\
\hline SDZ28 & ------------- & No interaction & -100.21 & -63.54 \\
\hline SDZ29 & N-Asn48(3.37); N-Asn48(3.10); & 3 & -94.32 & -60.92 \\
\hline
\end{tabular}




\begin{tabular}{|c|c|c|c|c|}
\hline & $\mathrm{N}-\mathrm{Asn} 48(3.26)$ & & & \\
\hline SDZ30 & N-Glu109(2.93); N-Tyr49(3.44) & 2 & -195.73 & -38.99 \\
\hline SDZ31 $^{*}$ & $\begin{array}{l}\text { N-Asn110(3.08); N-Glu109(3.31); } \\
\text { N-Asn48(2.95); N-Asn48(3.31); } \\
\text { N-Asn48(3.24) }\end{array}$ & 5 & -101.53 & -65.52 \\
\hline SDZ32 & N-Glu109(2.87) & 1 & -106.23 & -61.19 \\
\hline SDZ33 & ------------- & No interaction & -89.66 & -64.73 \\
\hline SDZ34 & N-Lys114(2.97) & 1 & -73.51 & -56.33 \\
\hline SDZ35 & ------------- & No interaction & -85.24 & -61.58 \\
\hline SDZ36 & ------------- & No interaction & -88.49 & -65.07 \\
\hline SDZ37 & N-Tyr49(2.81); O-Cys47(1.82) & 2 & -87.45 & -65.84 \\
\hline SDZ38 & N-Asn110(3.07); N-Glu109(3.21) & 2 & -66.51 & -51.83 \\
\hline SDZ39 & ------------- & No interaction & -99.91 & -69.61 \\
\hline SDZ40 & N-Asn110(3.05) & 1 & -86.41 & -63.89 \\
\hline SDZ41 & $\mathrm{N}-\operatorname{Asn} 110(3.40)$ & 1 & -83.43 & -47.09 \\
\hline SDZ42 & $\mathrm{N}-A s n 110(2.60)$ & 1 & -71.04 & -58.32 \\
\hline SDZ43 & N-Asn110(2.99); N-Glu109(2.82) & 2 & -63.58 & -53.43 \\
\hline SDZ44 & N-Glu113(3.10) & 1 & -87.71 & -64.35 \\
\hline SDZ45 & N-Asn48(2.93) & 1 & -72.87 & -52.22 \\
\hline SDZ46 & --------------- & No interaction & -94.65 & -55.53 \\
\hline SDZ47 & $\mathrm{N}-\mathrm{Asn} 48(3.31)$ & 1 & -93.74 & -63.53 \\
\hline SDZ48 & $\mathrm{N}-A s n 110(3.55)$ & 1 & -95.26 & -65.48 \\
\hline SDZ49 & --------------- & No interaction & -92.66 & -62.94 \\
\hline SDZ50 & N-Asn48 (2.95) & 1 & -77.24 & -61.43 \\
\hline SDZ51 & ------------ & No interaction & -118.29 & -68.69 \\
\hline SDZ52 & ------------- & No interaction & -102.83 & -39.19 \\
\hline SDZ53 & N-Tyr49 (2.93) & 1 & -80.71 & -39.13 \\
\hline SDZ54 & N-Asn110(3.27); Glu109(3.110 & 2 & -70.21 & -53.495 \\
\hline SDZ55 & $\begin{array}{l}\text { Asn110(3.09); N-Asn110(3.10); } \\
\text { N-Glu109(3.20) }\end{array}$ & 3 & -69.85 & -54.10 \\
\hline SDZ56 & $\mathrm{N}-A s n 110(3.20)$ & 1 & -76.51 & -58.24 \\
\hline SDZ57 $7^{*}$ & $\begin{array}{l}\text { O-Cys47(1.47); N-Glu109(3.15); } \\
\text { N-Asn48(3.46); N-Asn110(3.10); } \\
\text { N-Asn110(2.76) }\end{array}$ & 5 & -74.14 & -55.43 \\
\hline SDZ58* & $\begin{array}{l}\text { O-Thr96 (3.10); O-Asn110 (2.64); } \\
\text { N-Asn48(2.69); N-Asn48 (3.17); } \\
\text { N-Asn48 (3.07); N-Asn48(2.91) }\end{array}$ & 6 & -78.17 & -47.33 \\
\hline SDZ59* & $\begin{array}{l}\text { O-Asn110(2.60); O-Thr96 (2.92); } \\
\text { N-Asn48(3.07); N-Asn48(2093); } \\
\text { N-Asn48(3.08); N-Asn48 (2.76) }\end{array}$ & 6 & -85.13 & -61.33 \\
\hline
\end{tabular}


World Journal of Advanced Research and Reviews, 2020, 07(03), 166-180

\begin{tabular}{|l|l|l|l|l|}
\hline \multirow{2}{*}{ SDZ60* $^{*}$} & $\begin{array}{l}\text { O-Glu92(3.30); O-Asn93(3.15); } \\
\text { N-Asn48(3.02); N-Asn48(3.10); } \\
\text { N-Asn48(3.09); N-Asn48(3.35) }\end{array}$ & 6 & -84.87 & -68.13 \\
\hline SDZ61* & $\begin{array}{l}\text { N-Lys114(3.00); N-Lys114(3.12); } \\
\text { N-Asn48(2.85); N-Asn48(2.85); } \\
\text { O-Glu50(3.37) }\end{array}$ & 5 & -96.28 & -63.94 \\
\hline SDZ62* & $\begin{array}{l}\text { O-Cys47(2.88); N-Glu109(3.11); } \\
\text { N-Asn110(3.19); N-Asn110(3.14) }\end{array}$ & 4 & -87.15 & -49.55 \\
\hline \multirow{3}{*}{ SDZ63* } & $\begin{array}{l}\text { O-Gln33 (3.08); O-Gln50(2.83); } \\
\text { N-Glu109(3.47); N-Asn110(3.18); } \\
\text { O-Thr96 (3.46); N-Asn110 (2.96); } \\
\text { N-Glu109(3.48) }\end{array}$ & 7 & -101.75 & -43.08 \\
\hline SDZ64* & $\begin{array}{l}\text { O-Glu50(2.86); O-Gln33(3.10); } \\
\text { N-Asn110(3.13); N-Glu109(3.20); } \\
\text { N-Glu109(3.41); N-Asn110(3.07) }\end{array}$ & 6 & -104.88 & -50.11 \\
\hline SDZ65* & $\begin{array}{l}\text { N-Lys114 (3.38); O-Asn93 (2.87); } \\
\text { O-Thr96 (3.09); N-Asn48 (3.22); } \\
\text { N-Asn48 (2.71); N-Asn48(3.03) }\end{array}$ & 6 & -100.01 & -73.01 \\
\hline SDZ66* & $\begin{array}{l}\text { N-Glu113(2.88); N-Arg116 (3.20); } \\
\text { N-Arg116 (3.17); O-Glu50(2.63); } \\
\text { N-Asn110(3.26); O-Asn48(3.57) }\end{array}$ & 6 & -103.91 & -73.48 \\
\hline
\end{tabular}

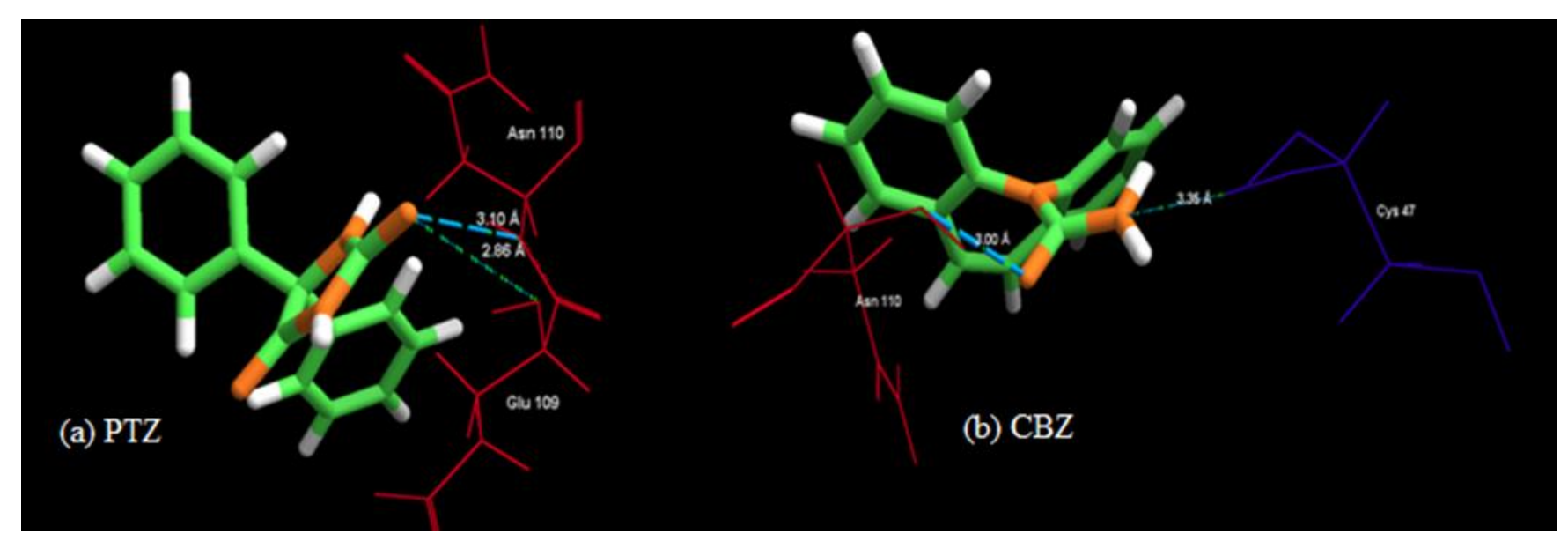

Figure 6 Interaction of standard drug (a) PTN and (b) CBZ with PDB 1OHV 


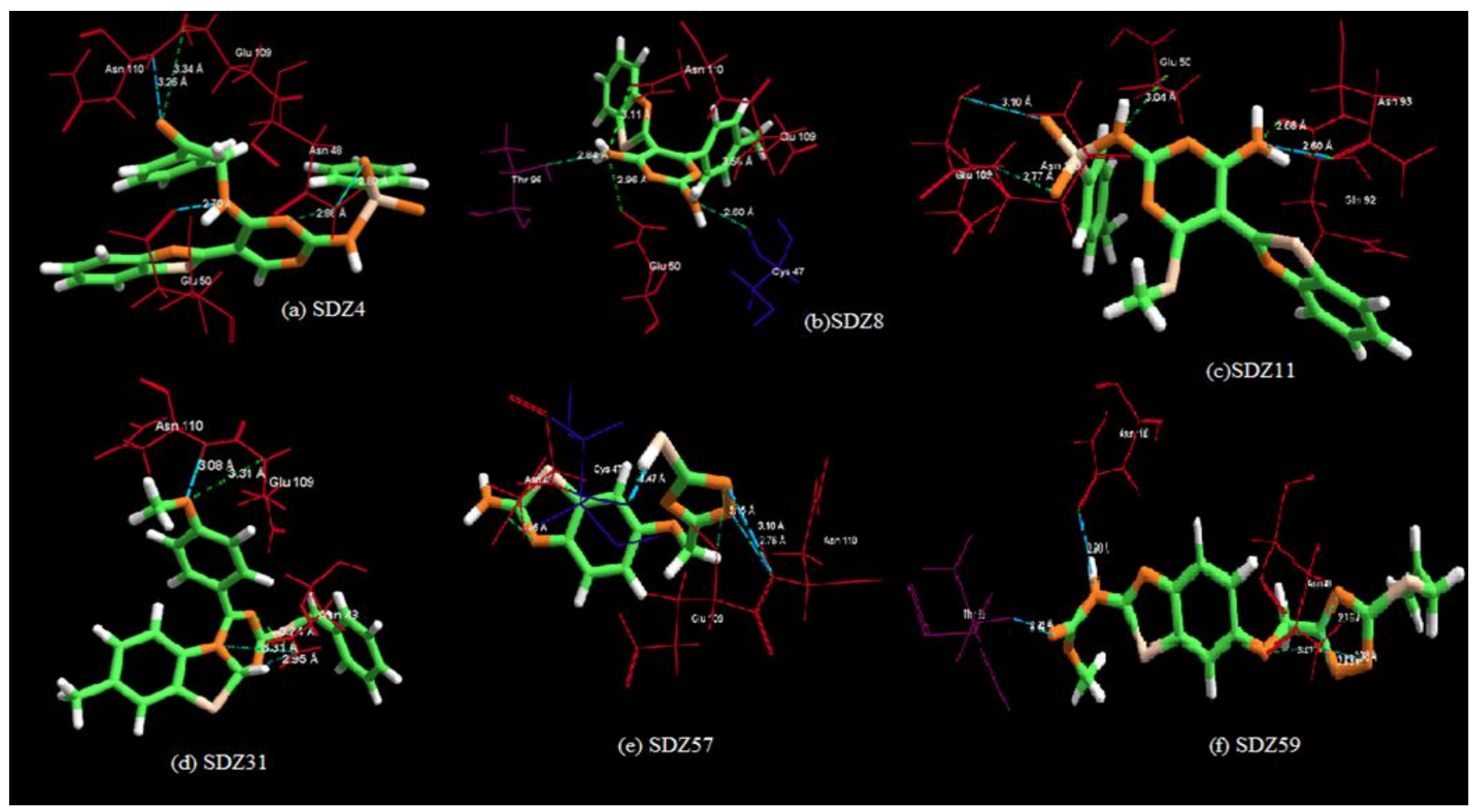

Figure 7 Interaction of compounds (a) SDZ4, (b) SDZ8, (c) SDZ11, (d) SDZ31, (e) SDZ57, and (f) SDZ59 with PDB $10 \mathrm{HV}$.

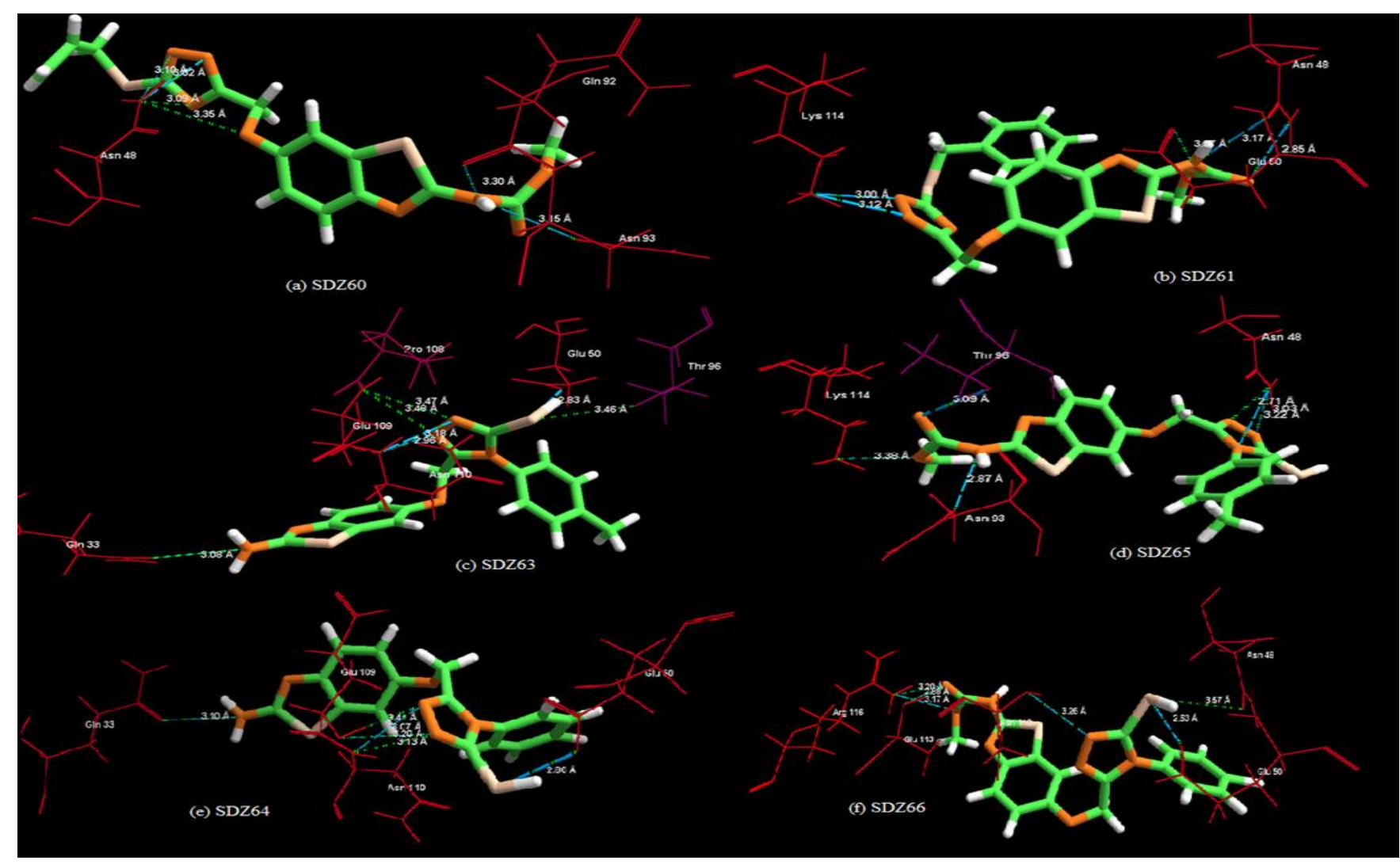

Figure 8 Interaction of compounds (a) SDZ60, (b) SDZ61, (c) SDZ63, (d) SDZ65, (e) SDZ64, and (f) SDZ66 with PDB $10 \mathrm{HV}$. 


\section{Conclusion}

Docking experiments have allowed us to learn how benzothiazole attaches to activate their GABA restrictive behaviors. Such investigations are exceptionally beneficial during the synthesis of selected substances, which efficiently inhibits GABA-AT enzyme. It was also examined from a higher point of view that receptor structure plays a critical role in influencing the drug action. Thus, it can be concluded that the above designed benzothiazole derivatives can hold great importance, particularly as anticonvulsant agents, as identified by in silico methods in the present study.

\section{Compliance with ethical standards}

\section{Acknowledgments}

We express our sincere thanks to the Director of the Institute of Pharmaceutical Sciences, Kurukshetra University, Kurukshetra for providing necessary research facilities.

\section{Disclosure of conflict of interest}

The authors declare no conflict of interest.

\section{References}

[1] Meng X, Zhang H, Mezei M, Cui M. Molecular docking : A powerful approach for structure-based drug discovery. Curr Comput Aided Drug Des. 2011; 7(2): 146-57.

[2] Ferreira LG, Dos Santos RN, Oliva G, Andricopulo AD. Molecular docking and structure-based drug design strategies. Molecules. 2015; 20(7): 13384-421.

[3] Kitchen DB, Decornez H, Furr JR, Bajorath J. Docking and scoring in virtual screening for drug discovery: Methods and applications. Nat Rev Drug Discov. 2004; 3(11): 935-49.

[4] Agarwal S, Mehrotra R. An Overview of Molecular Simulation. JSM Chem. 2016; 4(2): 1024.

[5] Lorber DM, Shoichet BK. Flexible ligand docking using conformational ensembles. Protein Sci. 1998; 7(4): 93850 .

[6] Benzothiazole - Wikipedia [Internet]. [cited 2020 Jul 9].

[7] Partap S, Akhtar MJ, Yar MS, Hassan MZ, Siddiqui AA. Pyridazinone hybrids: Design, synthesis and evaluation as potential anticonvulsant agents. Bioorg Chem. 2018; 77: 74-83.

[8] Storici P, De Biase D, Bossa F, Bruno S, Mozzarelli A, Peneff C, Silverman RB, Schirmer T. Structures of $\gamma$ Aminobutyric Acid (GABA) Aminotransferase, a Pyridoxal 5'-Phosphate, and [2Fe-2S] Cluster-containing Enzyme, Complexed with $\gamma$-Ethynyl-GABA and with the Antiepilepsy Drug Vigabatrin. J Biol Chem. 2004; 279(1): 363-73.

[9] Zein F, Zhang Y, Kang YN, Burns K, Begley TP, Ealick SE. Structural insights into the mechanism of the PLP synthase holoenzyme from Thermotoga maritima. Biochemistry. 2006; 45(49): 14609-20.

[10] Czapinski P, Blaszczyk B, Czuczwar SJ. Mechanisms of action of antiepileptic drugs. Curr Top Med Chem. 2005; 5: 3-14.

[11] Azzam RA, Osman RR, Elgemeie GH. Efficient Synthesis and Docking Studies of Novel Benzothiazole-Based Pyrimidinesulfonamide Scaffolds as New Antiviral Agents and Hsp90 $\alpha$ Inhibitors. ACS Omega. 2020; 5(3): 164055.

[12] Firdaus JU, Habib A, Siddiqui N, Alam O, Naim MJ, Partap S, Sahu M. Design, synthesis, and molecular docking study of benzothiazolotriazine derivatives for anticonvulsant potential. Arch Pharm (Weinheim). 2018; 351(12): 1-9.

[13] Dar AA, Shadab M, Khan S, Ali N, Khan AT. One-Pot Synthesis and Evaluation of Antileishmanial Activities of Functionalized S-Alkyl/Aryl Benzothiazole-2-carbothioate Scaffold. J Org Chem. 2016; 81(8): 3149-60.

[14] Omar AMME, Aboulwafa OM, Issa DAE, El-Shoukrofy MSM, Amr ME, El-Ashmawy IM. Design, facile synthesis and anthelmintic activity of new: 0 -substituted 6-methoxybenzothiazole-2-carbamates. Part II. Medchemcomm. 2017; 8(7): 1440-51. 